



\section{$[r Y]$}



 \\ المستحلص
}

استهدف البحث دراسة مشكلة الرضا الوظيفى فى بيئة العمل فى الاجهزة الإدارية ومدى في الإنه














الكتب والمراجع العربية والأجنبية، والدوريات العربية والأجنبية، والتقارير والبحوثة والنية والمقالات
























فى إتخاذ القرارات فى تصريف أمور العمل، وقد يرجع ذللك إلى جودة الإنشراف والتوجية

$$
\text { المجلد الخامس والثلاثون الجزء الاول ديسمبر } 7 \text { ـ ا ب }
$$


والمساعدة من الرئيسى، وأيضا درجة الإستقلالية فى إتخاذ القرارات ومعاير وفرص الترقية، والأهم معدل وعدالة العائد المادى من أجور وحوافز وومزايا إضافية.

\section{$\sin$}

إن تاريح الإدارة والإصلاح الإداري في العالم قديم جداً، تعود أصوله إلى رغبة المجتمعات التي تريد أن تحسن من أدائها الإداري والإنتاجي، وفي جميع مفاصل الإدياة الإني

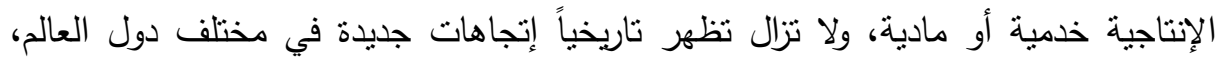
وخاصة المتقدمة منها، لتؤكد ضرورة تحديث الأنظمة والهياكل الإدارية، وأساليبها وتقنيات عملها، وذلك من أجل رفع وتحسين مستوى كفاءة الأجزة العامة، وقد قدم علماء الإدارة مجموعة كبيرة من المصطلحات الدالة على عمليات التحديث والتطوير، منل (الإصلاح

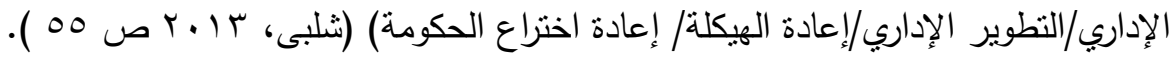


إعادة النظر في مجالات الأعمال من جوانب عدة لاكتساب المنظمة مقومات البقاء، باعتبارها نظام مفتوح، وتعتبر مشكلة العمالة الفائضة أحد الجوانب الهامة في ظل زيادة لهادة حدة المنافسة والتطورات التكنولوجية السريعة والمتلاحقة التي أدت إلى خروج بعض المنظمات من مجال العمل نتيجة لعدم قدرتها على الصمود، والفشل في وضع استراتجيات تكسبها مقومات صحيحة، حيث يعتبر جانب العمالة في منل هذه الظروف أحد الجوانب الهامة التي تنملها إعادة الهيكلة، والتي ما هي إلا إعادة تتظيم لمجموعة من الآليات لتطوير وتحسين القدرة

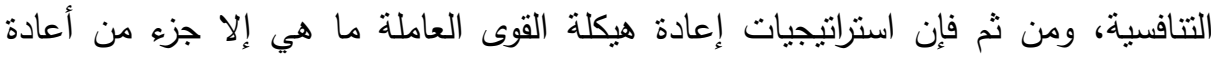

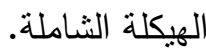
ولابد أن تتوافق الوظيفة مع من يشغلها، حيث انه لابد من وضع وصف للوظائف

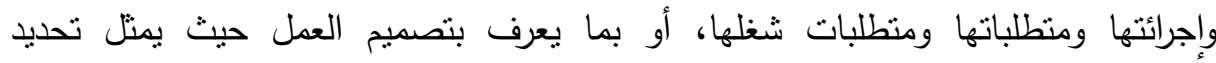
خصائص الوظائف والإعمال وسماتها وكفاءتها من اجل الاستفادة من كل وظيفة لتحقيق اكبر لهرب مستوى من الإنتاجية لتوفير الترابط بين الموظفين ووظائفهم، حيث يمكننا القول بأنه " يقصد

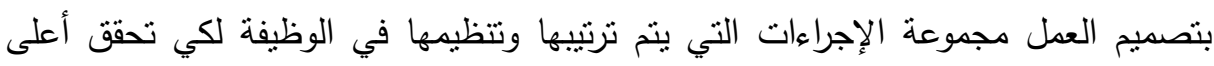


مسنوى من التلاؤم ما بين العاملين وأعمالهم أو وظائفهم وبما يحقق التوافق والتلاؤم الفعال

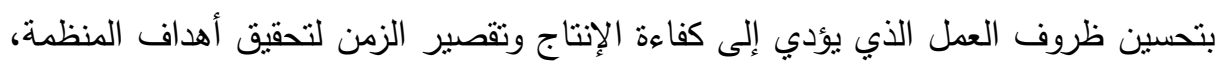

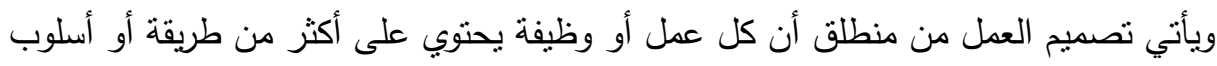
للأداء، وتختلف هذه الطرق فيما بينها من خلال اختلاف جودتها" ( احمد الكردي، • ب).

\section{Anand}

من خلال قيام الباحثون بإجراء دراسة استطلاعية لمجموعة من العاملين بجامعة القاهرة بمختلف المستويات الإدارية على النحو التالى ( الإدارة العليا بنسبة ؟\%، إدارة وسطى بنسبة

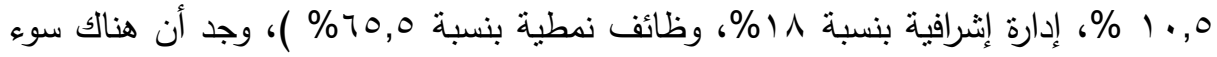
تنظيم ضمن الأجهزة الإدارية يعكس انخفاضاً في الأداء الكمي والنوعي، وضعفاً في التأقلم مع إنه



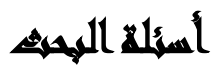

ما مدى تأثير إعادة الهيكلة على الرضا الوظيفى فى بيئة العمل فى الأجهزة الإدارية فى مصر؟ أسئله فرعية: مدنة

$$
\begin{aligned}
& \text { • ما المشكلات التي تعاني منها الأجهزة الإدارية ؟ } \\
& \text { • ما متطلبات إعادة الهيكلة ؟ }
\end{aligned}
$$



\section{أهمية الهبهث}

تتبع أهمية البحث من كونه يتتاول موضوع إعادة الهيكلة في مصر، وهو ذو خصوصية عالية وتأثنر كبير على مستوى حياة الأفراد والمنظمات والدولة بشكل عام، وبسبب أهنية موضوع إعادة الهيكلة في الوقت الراهن ومدى تأثثر إعادة الهيكلة فى مصر على الهى الرضا

$$
\text { المجلد الخامس والثلاثون الجزء الاول ديسمبر } 1 \text { ا ـ ب }
$$


الوظيفى فى بيئة العمل المصرية ـ وتعود أهمية الدراسة الى اهية الرضا الوظيفي لدى



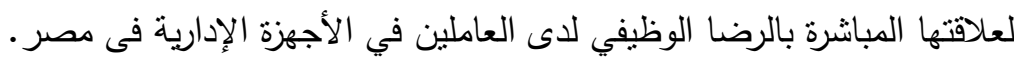

\section{أهما اهث المهثه}

يهدف البحث إلي تحقيق هدف رئيسى وهو قياس أثز إعادة الهيكلة على الرضا الوظيفى

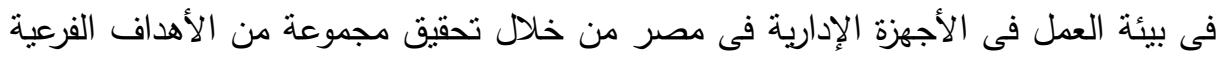
وهي :

توضيح لـفهوم إعادة الهيلكة والرضا الوظيفى وما يرنبط بهم. التعرف على منطلبات إعادة هيكلة المنشأة . دراسة أثز إعادة الهيلكة على الرضا الوظيفى فى مصر.

\section{هروضر التراسما}

1 - لا توجد علاقة ذات دلالة إحصائية بين إعادة الهيكلة والرضا الوظيفى فى بيئة العمل فى الأجهزة الإدارية فى مصر.

r- توجد علاقة ذات دلالة إحصائية بين إعادة الهيكلة والرضا الوظيفى فى بيئة العمل فى

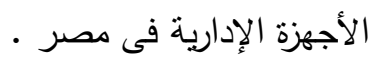

\section{andlingat}

الحدود المكانية: جامعة القاهرة، حيث أن أحد الباحثين من العاملين بجامعة القاهرة، وقد تعرف على بعض المشاكل التى تواجه العاملين بالجامعة وملاحظته لعدم وجود الرضا الوظيفى لديهم.

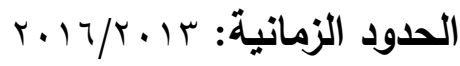






اعتمد البحث على المنهج الوصفي التحليلي الذي يتضمن استخدام الأسلوب الميداني


الدراسة كما تعتمد على المسح المكتبي للاستفادة من الكتب والدوريات العلمية في بناء الإطار



مصادر جمع البيانات: نم الاعتماد فى هذا البحث على مصدرين لجمع المعلومات: أ- المصادر التي إنتهجت مبدأ المسح المكتبي والأدبيات الإدارية الباحثة في موضوع إعادة

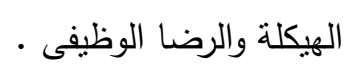

ب- المصادر الأولية والتي اعتمدت على البيانات والمعلومات التي سيتم جمعها من أفراد عينة

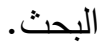

\section{الإطار النظليى اللهيه}

المبحث الأول: إعادة الهيكلة أولاً: مفهوم إعادة الهيكلة: تعرف إعادة الهيكلة بصفة عامة بإنها عملية تغيير مدروسة

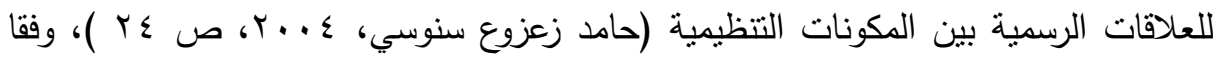
لهذا المفهوم والذى يقصد به مجموعة الاستراتجيات والخطط والبرامج والسياسات التي تضعها الإدارة لتخفيض التكاليف وتحسين كفاءة الأداء، واعتبار تخفيض العمالة، وإدارة العمالة

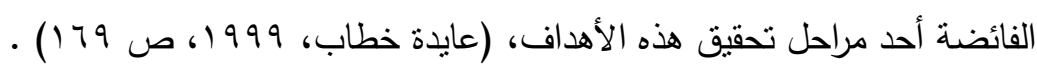








الهيكل التتظيمي بالمؤسسة والغرض من وراء ذللك تحسين كل من الكفاءة والفعالية . 
وبما أن تصميم العمل شي أساسى لنجاح برامج الموارد البشرية فيجب أن نوضح أهميته والتي من الممكن إدراجها كما يلي: ثانياً: أهمية تصميم العمل:

ا ـ تعريف شاغل الوظيفة بالمهام الموجودة في الوظيفة، وبالسلطات والعلاقات من خلال الوصف الوظيفى المعتمد. r. يتم اختبار العاملين بناء على مواصفات شاغل الوظبفة المحددة في الوصف. r. يتم تحديد أجر الوظيفة بناء على ما يعكسه وصف الوظيفة من أهمية لها.


وصف الوظيفة. ه. تتم الترقية للوظيفة بناء على ما تتوافر لدى الفرد من مواصفات مذكورة في بطاقة وصف الوظيفة" (منتدى التتمية البشرية وتطوير الذات ).

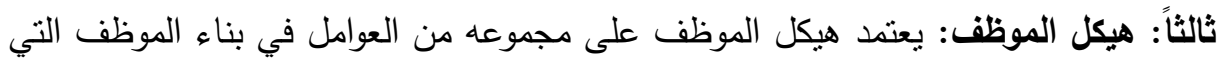



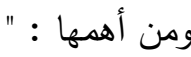
1- المستوى العلمي والمؤهلات التي بمتلكها الفرد مثل الثهادات الدراسية . r- مجموع الخبرات والمؤهلات الثخصية . r- القدرة الثخصية على تطوير الذات ( وليس بالاعتماد على المنظمة ). ع - الإمكانيات الوظيفية المتوفرة في المنظمة والتي تساعد على تأهيل الموظفين لمستويات ويتم تحديد المسار الوظيفي لأي موظف وفق هذه العوامل بعد دراستها واختبارها لكل موظف ووظيفة. 
رابعاً: بناء الهيكل الوظيفي:

يعرف الهيكل الوظيفي بأنه " يتميز بمبدأ التدرج الذي يحدد العلاقات نحو الاتجاهات


على أساس الوظائف فانه لا يبتعد عن المظهر الهرمي، ولكل منصب في الهي التتظيم دور يناسبه




ويفترض انه وضع لتوفير الأشخاص المناسبين وهذا يدخل ضمن إطار تحليل الوظائف مونف وتوظيف الموارد البشرية في المكان المناسب من أجل التقبد بإستراتيجية المؤسسة الرامية لتحقيق أهداف المؤسسة" (الموسوعة الحرة).

من خلال التعاريف السابقة نستطيع القول أن الهيكل التتظيمي هو أساس معرفة السلطة ونوع الوظيفة في المنظمة ( الجامعة الجزائرية، الهيكل النتظيمي، منتدى العلوم الاقتصادية،

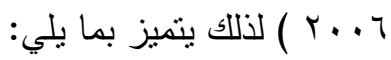


r. تسهيل تحديد أدوار الأفراد في المنظمة ويحدد من يمنتل لمنطلبات المنظمة وليس العكس.

r. المساعدة في اتخاذ القرار وممارسة القوة." خامساً: إعادة هيكلة العمالة هي: • مجموعة الأنشطة والعمليات التي تصمم لزيادة كفاءة التنظيم ورفع الإنتاجية، وتحسين

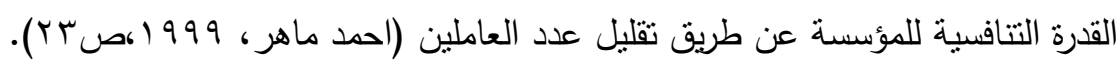
• مجموعة التصرفات التي تتخذ داخل المنظمة وتؤدي إلى تخفيض جوهري في عدد العاملين

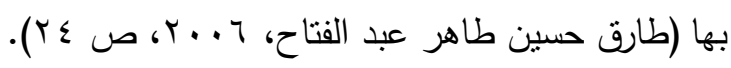
• عملية إدارية تقوم بها المؤسسة لتقليل قوة العمل من خلال التسريح والتقاعد المبكر • • تغيير العمليات التي يقوم بها الأفراد من خلال حذف بعض الأنشطة أو إعادة تصميمها

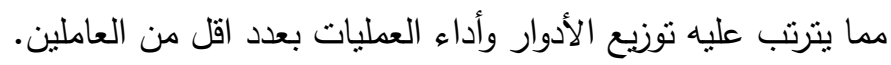




المبحث الثاني: الرضا الوظيفى: - الرئ

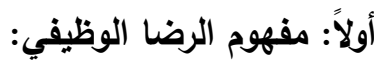

يعتبر مفهوم الرضا من أكثر مفاهيم علم النفس التنظيمي غموضا، ذلك لأنه حالة التهائ


ظهور الدئات من البحوث والدراسات حول هذا الموضوع، حيث تعددت واختلفت التعريفات التي حاولت تحديد مفهوم الرضا الوظيفي.







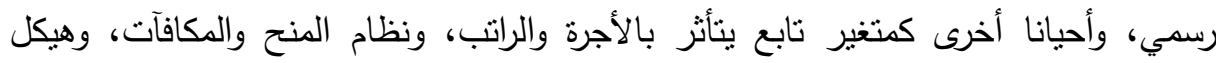
السلطة، ونظام اتخاذ القرارات وغير ذلك من المواضيع والمتغيرات النفسية والإجتماعبة

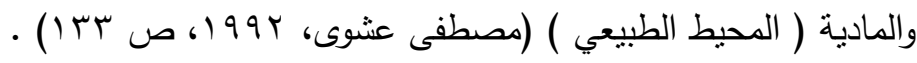

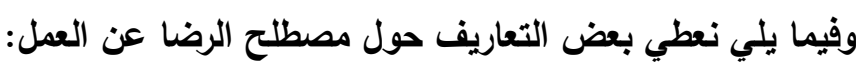

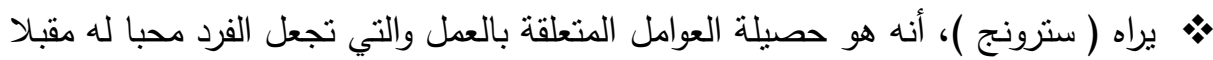









ه. " بعرفه كل من ( سارتن، وكان ) بأنه شعور جارف بالإنتماء إلى الجماعة، وهو محصلة



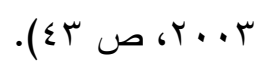

يمكن القول أن الرضا الوظيفي هو مفهوم مركب وله عدة أوجه، وأنه حالة ذهنية



$$
\text { طموحه ويحقق رغباته ويتناسب مع ميوله وقداته ويثبع حاجاته. }
$$


ثانياً: العوامل المؤثرة على الرضا الوظيفي :

هناك عدد من العوامل المؤثرة على درجة الرضا الوظيفي، والتي لابد للإدارة من أن الن النماني

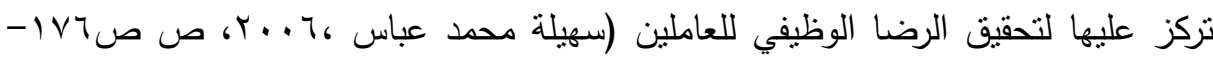
IVV

1-الأجور والرواتب: يتجه بعض الكتاب الدحدثين بأن الأجر لا يمنل مصدر إثباع إلا

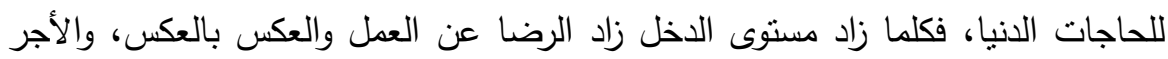

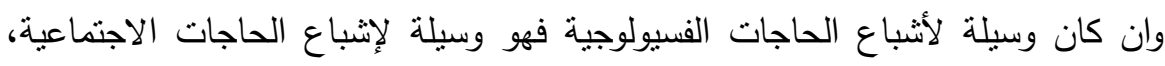

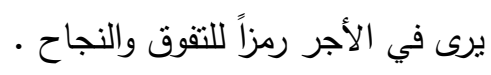
ץ-محتوى العمل وتتوع المهام: يمتل محتوى العمل وما يضمنه من مسؤولية وصداحية ودرجة التتوع في المهام أهمية الفرد، حيث يشعر الفرد بأهميته عندما يمنح صلاحيات

$$
\text { لإنجاز عمله، ولذلك يرتفع مستوى رضاه عن العمل. }
$$

r- إمكانية الفرد وقدراته ومعرفته بالعمل: ينوقف الأداء على متغيري الرغبة في العمل والقدرة

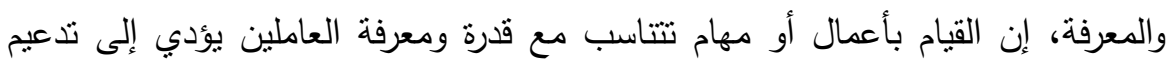

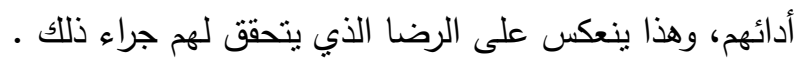
ع-فرص التطور والترقية المتاحة للفرد: إن المنظمة التي تتيح للإفراد فرصة التزقية وفقاء لتهاء للكفاءة، تساهم في تحقيق الرضا الوظيفي، إذ أن إثباع الحاجات العليا ( التطور والنمو)

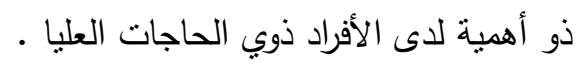

ه-نمط القيادة والإثراف: توجد علاقة بين نمط القيادة ورضا العاملين، فالنمط القيادي

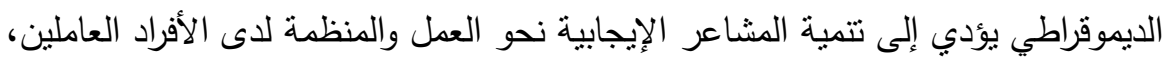

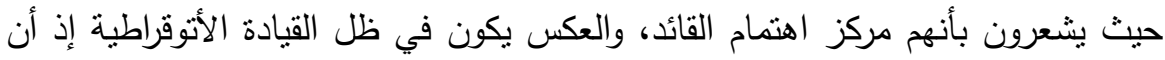

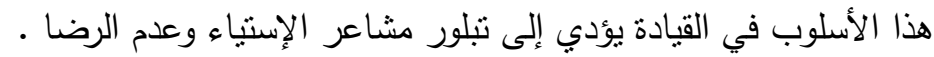
צ-جماعة العمل: تؤثر جماعة العمل برضا الفرد بالقدر الذي تمثل هذه الجماعة مصدر

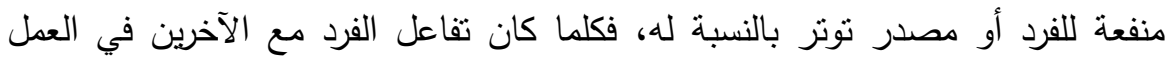
يحقق تبادل للمنافع بينه وبينهم كلما كانت جماعة العمل مصدر لرضا الفرد عن العمل .

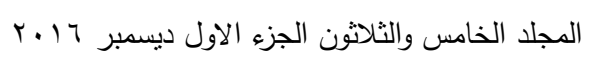


V-ساعات العمل: يمكننا أن نفترض انه بالقدر الذي توفر ساعات العمل للفرد حرية استخدام

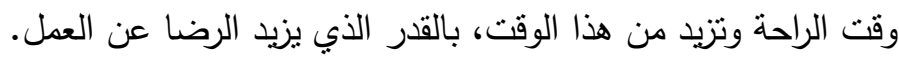

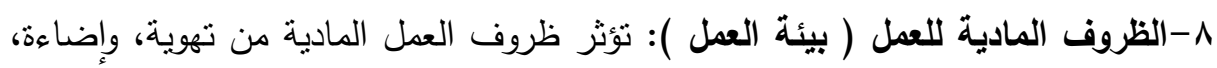
ورطوبة، وحرارة، وضوضاء على درجة تقبل الفرد لبيئة العمل، ولذلك فإن الظروف البيئية

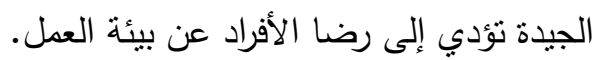

9-عدالة العائد: أوضح ( آدمز ) بأن الفرد يقارن معدل عوائده المستلمة قياسا بمدخلاته

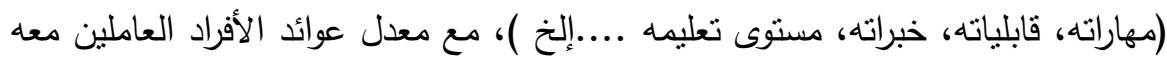
قياسا بمدخلاتهم، وإن نقص معدل ما بستلمه الفرد عن معدل غيره يشعره بعدم العدالة وتكون النتيجة الإستياء وعدم الرضا. ثالثاً - مسبيات الرضا الوظيفي: ما هي العوامل التي تؤدي بالعاملين إلى حالة الرضاء أوضيا. عدم الرضا بوظائفهج من خلال هذا السؤال يمكنا أن نقسم مسببات الرضا إلى قسمين:

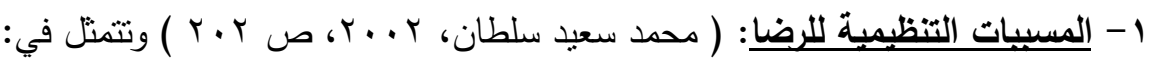
أ- ظروف عمل جيدة: كلما كانت ظروف العمل المادية منها مناسبة كلما ساعد ذلك أكثر على رضا العاملين منها: توفير الإضاءة - التهوية والحرارة.... ب-الإشراف: إن إدراك الفرد بمدى وجودة الإشراف الواقع عليه، تؤثر في درجة رضاه عن ت- سياسات المنظمة: تشير إلى وجود أنظمة عمل ولوائح وقواعد نتظيم العمل، وتوضح

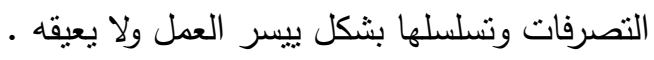

ث- نظام العوائد: يشعر الفرد بالرضا داخل المنظمة إن كان التوزيع للعوائد وفوائدها بالثكل المناسب وفقا لنظام محدد، وتتمتل في الترقيات، المكافآت، الحوافز ل... ج- تصميم العمل: وجود ضمان نسبي بالرضا عن العمل نتيجة لوجود تصميم سليم للعمل يتميز بالتتوع والتكامل والإستقلالية وتوافر معلومات كاملة. 


\section{r- المسبيات الشخصبة للرضا:}

أظهرت الدراسات أن الرضا عن العمل يتأثز بشخصية الفرد، فهناك أناس بطبيعتهم

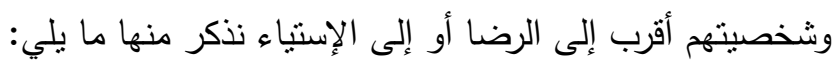

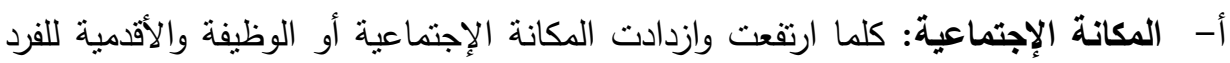

$$
\text { زاد رضا عن عمله . }
$$

ب- إحترام الذات: إذا كان لاى الفرد للإعتداد برأيه وذاته والعلو بقدره، كان أقرب أكثر إلى رصى

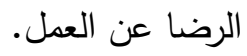

ت- تحمل الضغوط: قدرة تحمل الضغوط داخل المنظمة وكيفية التعامل معها لدى الفرد تجعله أكثر رضا، في حين وجود عقبات أو صعوبات فيكون الإستياء حليفه.

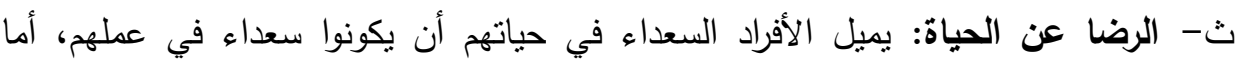
التعساء في حياتهم والغير راضيين عن نمط حياتهم بصفه عامة، فإنهم عادة ما ينقلون


رابعاً: قياس الرضا الوظيفي:

يمكن حصر الأساليب المستخدمة لقياس الرضا الوظيفى في الوقت الحاضر في نوعين الأول المقاييس الموضوعية والثانى المقاييس الذاتية.

ا- المقاييس الموضوعية: يعتبر متغيرى الغياب وترك الخدمة مؤشران على مستوى رضا العاملين في المنظمة، وسوف نعرض كيفية قياس كل من هذين المتغيرين: (بلقاسم فرجانى،

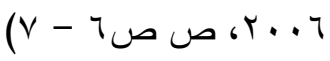

أ - الغياب: تعتبر درجة انتظام الفرد في عمله، أو بعبارة أخرى نسبة أو معدل غيابه مؤشرا

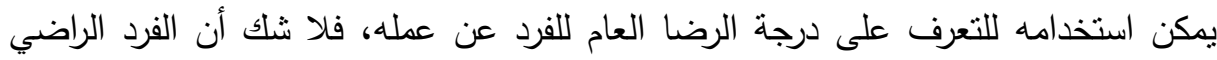

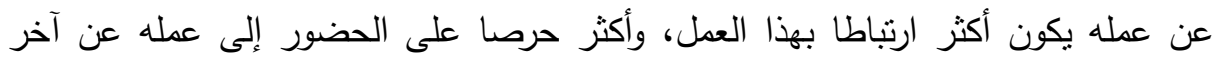
بشعر بالإسنياء تجاه العمل، وليس معنى هذا أن كل حالات الغياب تمثل حالات استياء تجاه 
ب - ترك العمل الإختياري (ترك الخدمة ): يشير ترك العمل إلى الإستقالة من المنظمة

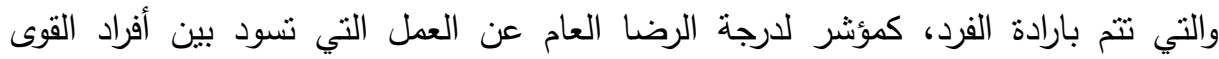

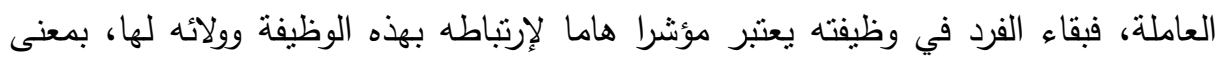

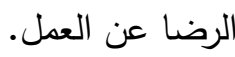

r - المقاييس الذاتية: تقوم هذه المقاييس على تصميم قائمة تتضدن أسئلة نوجه إلى الأفراد

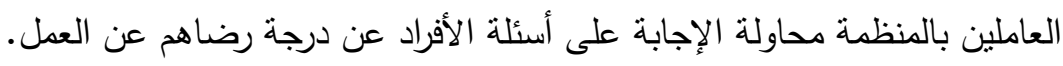
ومن أهم الطرق الرئيسية المستخدمة في قياس الرضا الرضها هي:

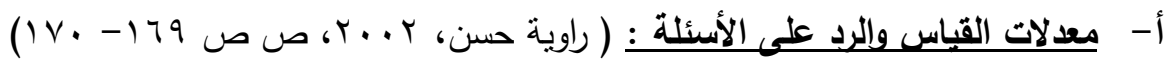
وهي من أكثر الطرق المستخدمة لقياس الرضا عن العمل وتستخدم معدلات القياس الكاملة وأشهرها:

• الأجندة الوصفية عن العمل: والأسئلة تتتاول بها خمسة جوانب مختلفة في العمل نفسه -

$$
\text { الأجر - فرص الترقية - الإثراف - الزملاء. }
$$

• طريقة المقاييس الرتبية وقوائم الإستقصاء: تعد قوائم الإستقصاء هي المدخل الثنائع

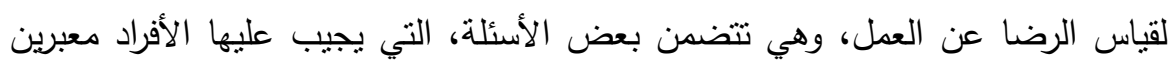

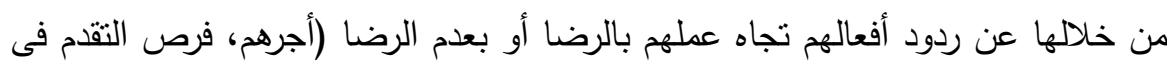

ب- أسلوب الأحداث الحرحة: وهو أسلوب أو إجراء آخر يمكن من خلاله قياس وتقييم رضا

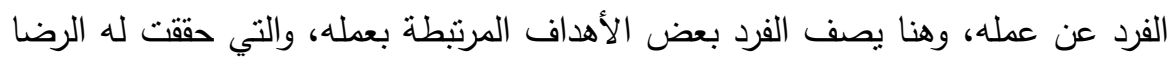

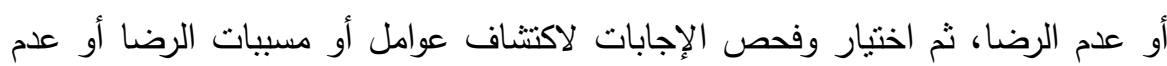

$$
\text { الرضا. }
$$

ت- المقابلات الثخصية: وهي الطريقة الأخرى لتقييم رضا الأفراد، وهي تتضمن مقابلة الأفراد بصفة شخصية ووجها لوجه، وسؤال الأفراد عن اتجاهتهم، فمن خلال سؤال الأفراد والحصول على اجاباتهم يمكن التعرف على الأسباب المختلفة التي سببت الإتجاهات المتعلقة بالعمل. 


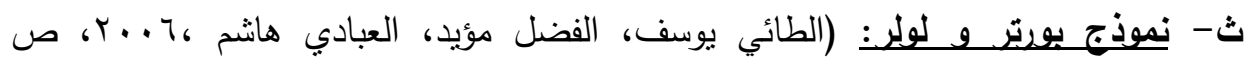

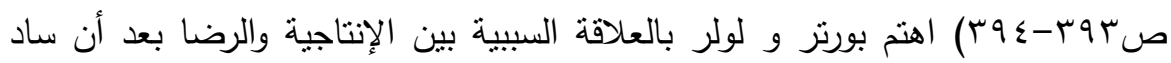

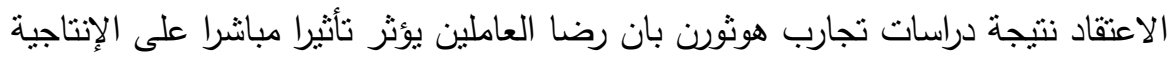

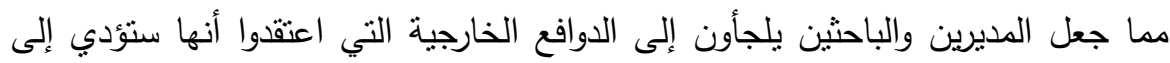

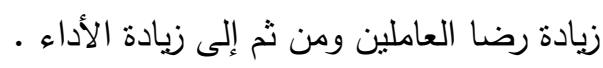

\section{إجبراعايت اللهبه}

\section{أولاً: عينة البحث ونسبة الاستجابة:}

أن مجتمع الدراسة يساوي . . 1 1 من الفئات الإدارية المختلفة للعاملين بجامعة القاهرة، وبالاعتماد على جداول العينات الإحصائية عند معامل ثقة 90 \%، وخطأ مسموح به في

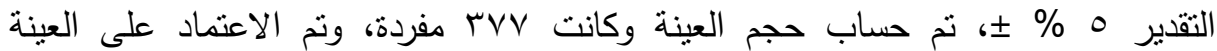
العشوائية الطبقية وفقاً للتوزيع النسبي للمستويات الإدارية المختلفة، وحسب كلبات ومعاهد الجامعة المختلفة وذلك طبقاً للجدول التالى:

\begin{tabular}{|c|c|c|c|}
\hline عدد الاستمارات & النسبة \% & عدد العاملين & الكلية \\
\hline$r$. & $0, r$ & $90 \leqslant$ & التجارة \\
\hline 19 & 0,1 & $19 \mathrm{~V}$ & الأداب \\
\hline 19 & $0, r$ & $9 \leq \varepsilon$ & الحقوق \\
\hline 19 & 0,1 & 110 & دار العلوم \\
\hline$\varepsilon$. & $1 \cdot, 0$ & $19 \leq$. & الزراعة \\
\hline ro & 7,0 & ITr. & الهندسة \\
\hline$r$. & $0, r$ & 901 & العلوم \\
\hline 77 & $1 v, 0$ & Trt. & الطب (القصر العينى) \\
\hline IV & $\varepsilon, 0$ & NYI & التمريض \\
\hline rr & ro & גדו & 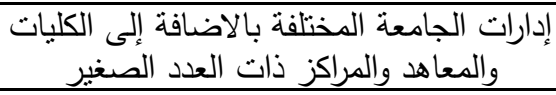 \\
\hline TVV & $1 \ldots$ & $1 \wedge r \ldots$ & الأجمالى \\
\hline
\end{tabular}


وبعد توزيع عدد rVV استنيان تم جمع عدد عه صالحة للتحليل الإحصائي وبذلك تكون نسبة الاستجابة و, ؟9 \%، وهي نسبة استجابة جيدة جداً مقارنة بالمجتمعات المماتلة لمجتمع الدراسة.

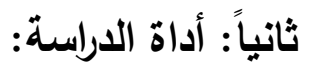

تم تصميم استمارة استقصاء والتي تضمنت مجموعة من العبارات لقياس اتجاهات أفراد

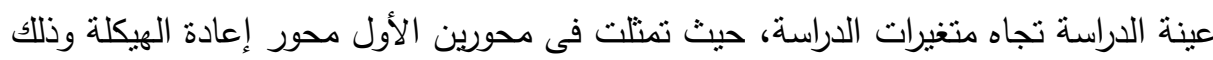

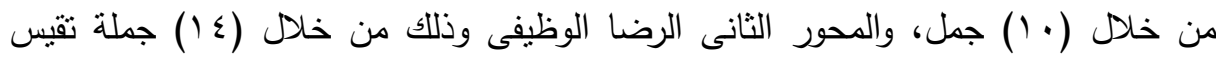

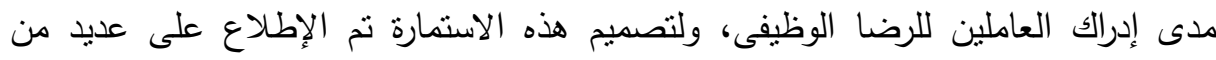

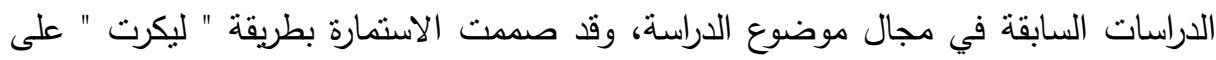
مقياس خماسي الاتجاه وكان لكل إجابة وزن مرجح.

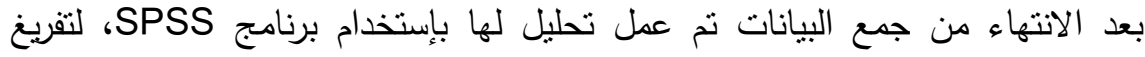

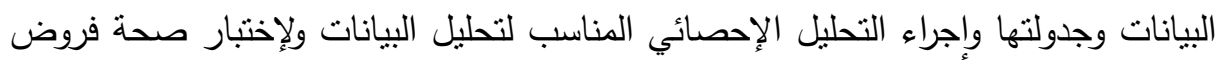

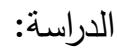

\section{معامل الصدق والثبات (ألفا كرونباخ):}

تم حساب معاملي الصدق والثبات (Cronbach Alpha) لأسئلة الاستقصاء في عينة الدراسة، وذلك لبحث مدى ثبات اسئلة الاستيان ولبحث مدى امكانية الاعتماد على هذه الاسئلة في التحليل. والجدول التالى يوضح قيم معاملي الصدق والثبات لدحاور الاستبيان. جدول رقم(1 ): معاملات الصدق والثبات

\begin{tabular}{|c|c|c|c|c|}
\hline معامل الثبات & معامل الصدق ألفاكرونباخ & عدد العبارات & اسم المحور & r \\
\hline$\cdot, 97$ & •, 94T & 1. & إعادة الهيكلة & 1 \\
\hline$\cdot, 9 \vee 9$ & $\cdot, 97$ & $1 \varepsilon$ & الرضا الوظيفي & r \\
\hline
\end{tabular}


من الجدول السابق يتضح أن معاملات الصدق والثبات مقبولة لأسئلة الاستبيان ككل، لان جميع قيم معاملى الصدق والثبات تجاوزت (0, • ) في عينة الدراسة، وبالثالي يمكن القول

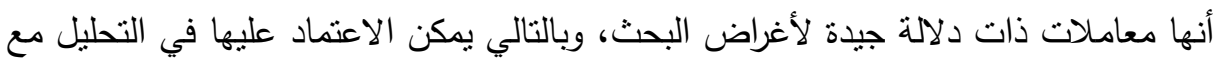
عدم استبعاد اي عنصر من عناصر المتغيرات محل الدراسة. وتطلب ذلك تطبيق بعض أساليب الإحصاء الوصفي والإحصاء التحليلي كالآتي:

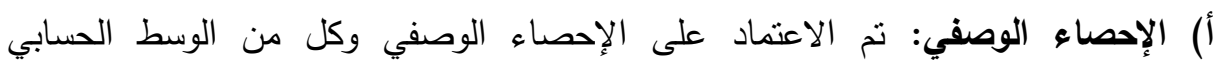
والانحراف المعياري لتوصيف متغيرات الدراسة من خلال البيانات التي تم جمعها وكذلك تم الاعتماد على معامل الفا كرو نباخ (Cron Bach's Alpha) والذي يستخدم لقياس مدى لونى الصدق والثبات للأسئلة الموجودة في الاستقصاء، وكذلك التأكد من مدى أهمية هذه الأسئلة بالاضافة الى استخدام معامل ارتباط بيرسون وذللك لقياس ثبات أداة الدراسة. ب) الإحصاء الاستدلالي: تم الاعتماد فى تحليل بيانات البحث على أساليب الإحصاء

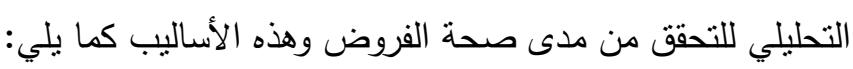
تحليل الانحدار الخطي البسيط: هو اسلوب احصائي يستخدم لاختبار أثز متغير مستقل واحد

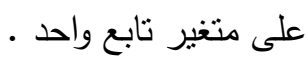
تحليل الانحدار الخطي المتعدد: هو اسلوب احصائي يستخدم لاختبار أثز اكثر من متغير مستقل على متغير تابع واحد . وذلك بطريقة المربعات الصغرى OLS والذي يحتوي على اختبار معاملات الانحدار

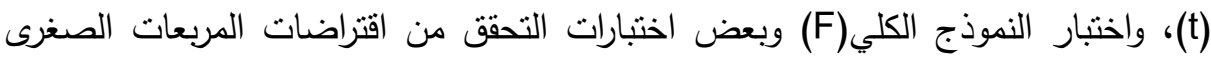
للتحليلين.

\section{ثالثاً :التحليل الاحصائي لأدوات الدراسة الميدانية} 1- الاحصاء الوصفي لنتائج الدراسة الميدانية:

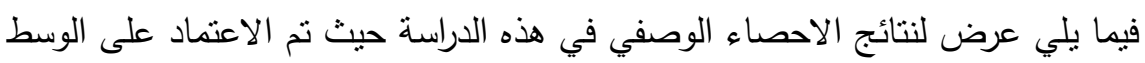

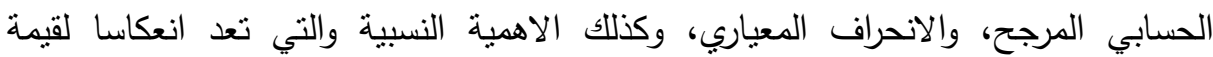
المتوسط المرجح في صورة نسبة مئوية :

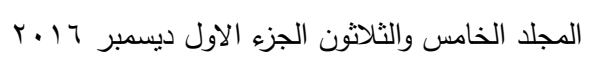




\section{نمائي السراسلة}

1- إعادة الهيكلة: تتاول الباحثون من خلا الدراسة الميدانية لتقدير إعادة الهيكلة للعاملين بجامعة القاهرة، والجدول التالى يوضح الوسط الحسابى المرجح والانحراف

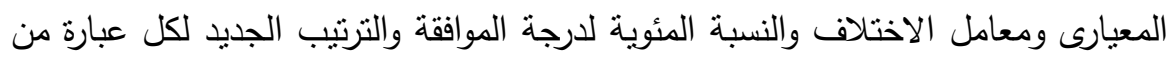

$$
\text { العبارات العشر لإعادة الهيكلة. }
$$

جدول رقم(ץ): المقاييس الإحصائية لوصف الجمل التى تفسر إعادة الهيكلة

\begin{tabular}{|c|c|c|c|c|c|c|}
\hline لمتربيب & 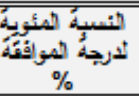 & 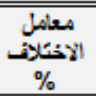 & المعيارى & لوزيط لخصابم & لفتـــرة & م \\
\hline , & or, 99 & or, va & $1, \times 99$ & $r, 70$ & 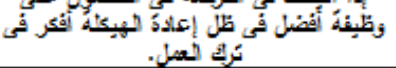 & \\
\hline$r$ & $01, r$ & $\leqslant A, A$ & i,ror & $r, 07$ & 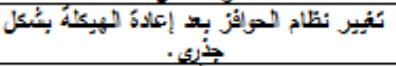 & 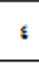 \\
\hline$r$ & $\cdot, \S V+1$ & $\cdot, \S \neg \vee \vee$ & $1, .99$ & r,to & 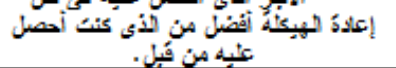 & 1 \\
\hline$\S$ & 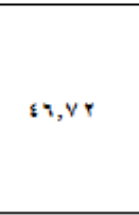 & $00,1$. & $1, Y A V$ & $r, r \leqslant$ & 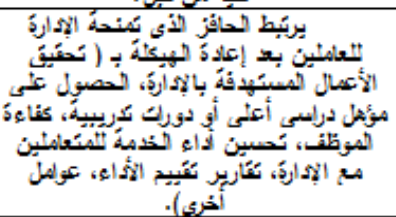 & $r$ \\
\hline o & $\vdots$ & or, vr & $1, Y 9 \times$ & $r, r$ & 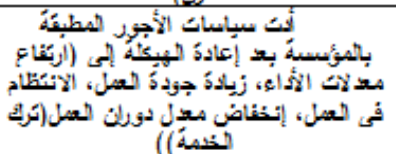 & $r$ \\
\hline 7 & $\leqslant x, \infty$ & $01, \leqslant r$ & $1,1 A \leq$ & $r, r$ & 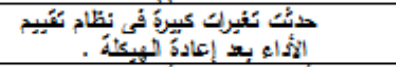 & 。 \\
\hline$v$ & $\leqslant 0,9 T$ & $€ \wedge, \vee \uparrow$ & 1,119 & $r, r$ & 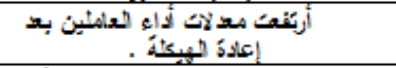 & 7 \\
\hline$\wedge$ & 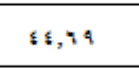 & $0 \cdot, 7 r$ & $1,1+1$ & $r, r T$ & 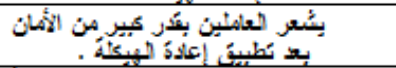 & . \\
\hline 9 & $\leqslant \varepsilon, \gamma q$ & $\$ 4, A r$ & $1,1+\pi$ & $r, r_{1}$ & 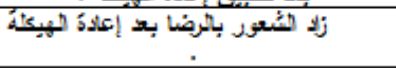 & $A$ \\
\hline 1. & 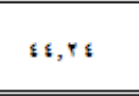 & 01,9 & $1,1 \leqslant A$ & $r, r)$ & 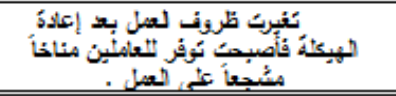 & $v$ \\
\hline
\end{tabular}


يتضح من الجدول السابق أن:

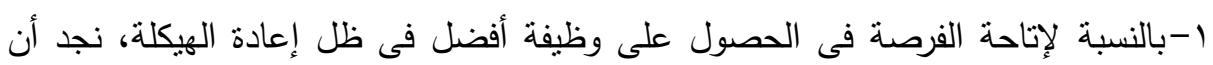
ro\% من العاملين بالجامعة لديهم الرغبة والتفكير فى نرك العمل الثئ الذى يدل على على أنى أنى

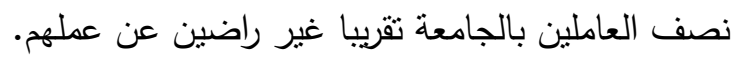

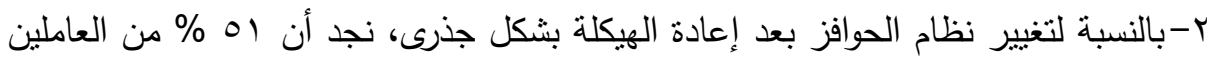
يرون ان هناك تغيير فى نظام الحوافز أما النصف الأخر من العاملين لا برون ذلك.

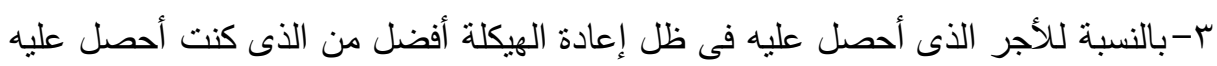

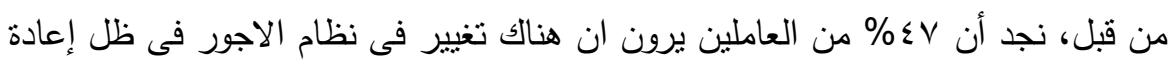
الهيكلة فى حين ان به\% من العاملين بالجامعة يرون العكس.

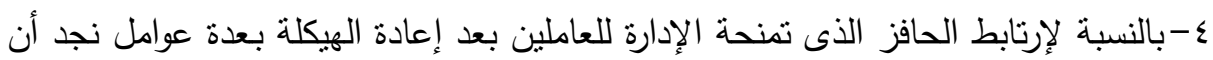
\%§7,V الأعمال المستهدفة بالإدارة، الحصول على مؤهل بالها دراسى أعلى أو دورات تدريبية، كفاءة

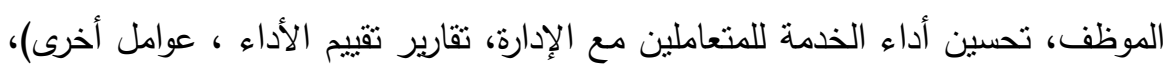
فى حين أن هنالك حوإلى به به من العاملين يرون غير ذلك.

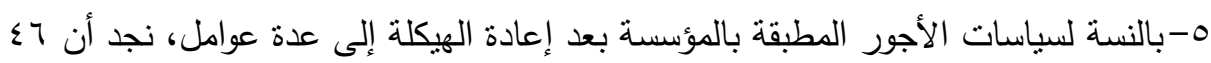

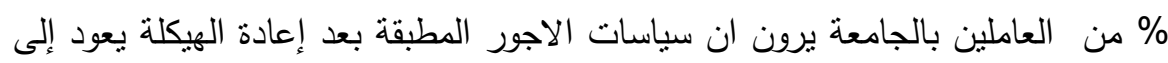

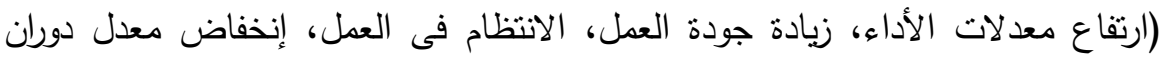

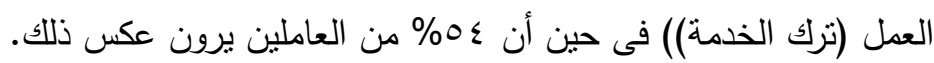

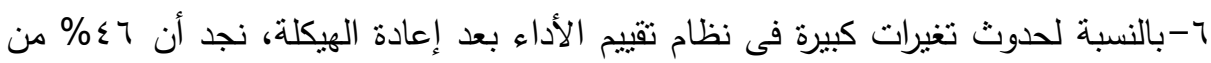

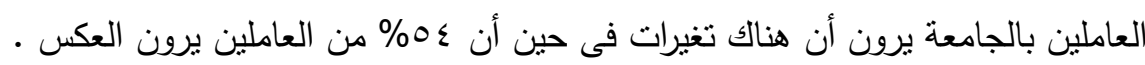

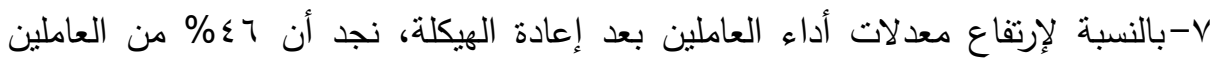

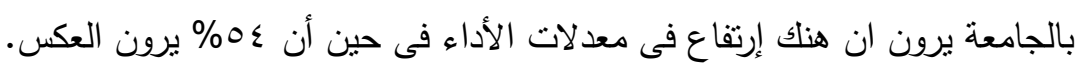

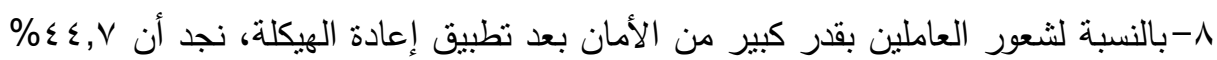

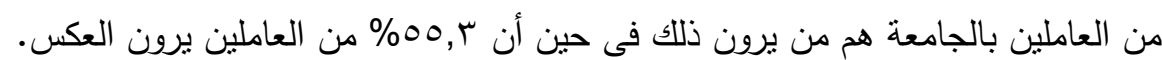

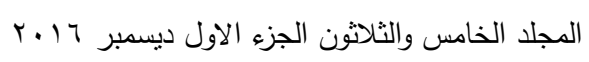


9-بالنسبة لزيادة الثعور بالرضا بعد إعادة الهيكلة، نجد أن ؟؟\% من العاملين بالجامعة

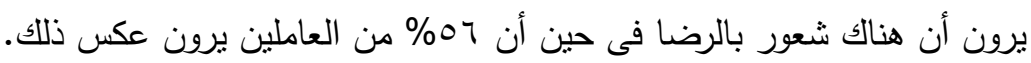

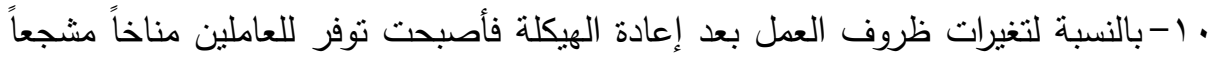

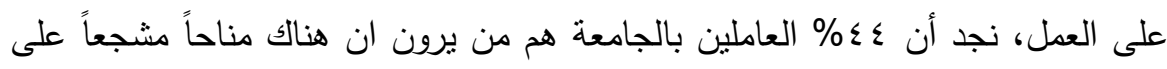

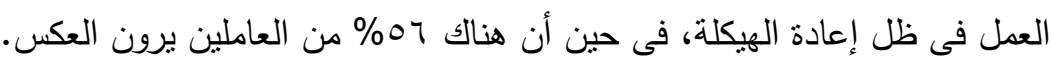
r- الرضا الوظيفى: الجدول التالى يوضح الوسط الحسابى المرجح والانحراف المعيارى ومعامل الاختلاف والنسبة المئوية لدرجة الموافقة والترتيب الجديد لكل عبارة من العبارات الاربعة عشر للرضا الوظيفى، وذلك لتقدير الرضا لوظيفى للعاملين بجامعة القاهرة . 
عمرو محمد أحمد عواد وآخرون

جدول رقم(r): المقاييس الإحصائية لوصف الجمل التى تفسر الرضا الوظيفى

\begin{tabular}{|c|c|c|c|c|c|c|}
\hline التربَبِب & 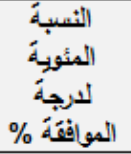 & $\begin{array}{c}\text { الاختَلافف } \\
\text { \% }\end{array}$ & المعِارب & المتربطى المبط & الفـــرة & م \\
\hline 1 & $09, \varepsilon q$ & $\varepsilon \vee, \wedge \varepsilon$ & $1, \varepsilon Y T$ & $r, 9 \mathrm{~V}$ & العـالقة مع زملاء العمل . & $\varepsilon$ \\
\hline r & or, 9 & $\varepsilon\urcorner, \varepsilon 0$ & $1, r)$ & $r, 7$ & مستوى الشعور بالاتجاز الهام عندما تؤدى أعمال & $v$ \\
\hline$r$ & $01, \varepsilon 1$ & $\varepsilon q, 00$ & $1, r \vee \varepsilon$ & r,or & 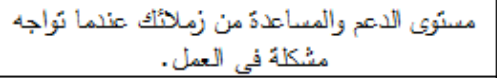 & $\wedge$ \\
\hline$\varepsilon$ & $\varepsilon q, \wedge r$ & $\varepsilon \wedge, 7 \varepsilon$ & I,Y Y r & $r, \varepsilon q$ & 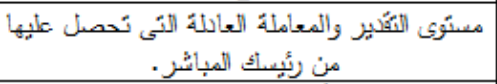 & $\circ$ \\
\hline$\circ$ & $\varepsilon q, r \wedge$ & $\varepsilon 0, \varepsilon T$ & I,Ir & $r, \varepsilon V$ & 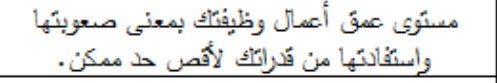 & it \\
\hline 7 & $\{\wedge, \vee\urcorner$ & $\varepsilon \Lambda, q$ & $1,1 V Y$ & $r, \varepsilon \varepsilon$ & 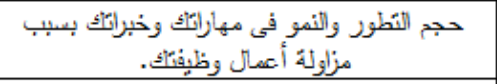 & $r$ \\
\hline $\mathrm{v}$ & $\varepsilon \wedge,+\Lambda$ & $\{\Lambda,+\}$ & 1,100 & $r, \varepsilon$ & 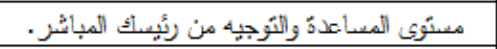 & 9 \\
\hline$\wedge$ & $\{\gamma, \varepsilon\rceil$ & $\{\Lambda, 0\}$ & $1,10 \mathrm{r}$ & $r, T V$ & 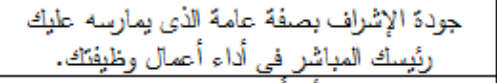 & it \\
\hline 9 & $\{0, \vee 7$ & 00,90 & $1, \mathrm{rA}$ & r, rq & 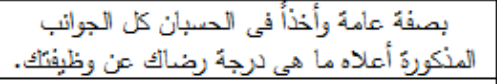 & $1 \varepsilon$ \\
\hline 1. & $\varepsilon \Gamma,\rceil \vee$ & $01, \varepsilon Y$ & $1,1 Y T$ & $r, 1 \Lambda$ & 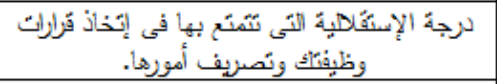 & 11 \\
\hline 11 & $\varepsilon r, T$ & or,, 7 & $1,1,9$ & $r, 1 r$ & 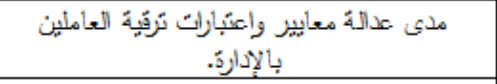 & 7 \\
\hline ir & $\varepsilon r, \varepsilon \Gamma$ & $\{9,10$ & $1, \cdot \varepsilon T$ & $r, r^{2}$ & 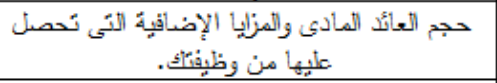 & 1 \\
\hline it & $\varepsilon r, r Y$ & or, 9 & 1,119 & $r, r^{2}$ & 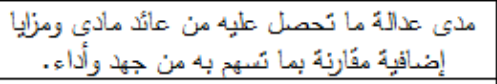 & 1. \\
\hline $1 \varepsilon$ & $r \Lambda, 09$ & 07,1 & $1,+1 r$ & 1,95 & 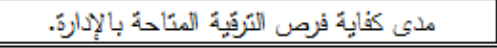 & $r$ \\
\hline
\end{tabular}

$$
\text { بتضح من الجدول السابق أن: }
$$

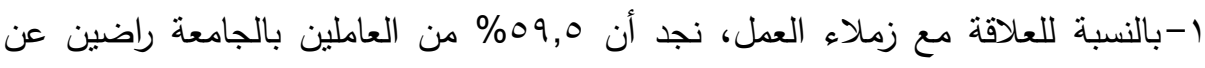

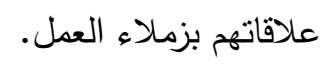

r-بالنسبة لمستوى الشعور بالانجاز الهام عندما تؤدى أعمال وظيفتلك، نجد أن بor\% من العاملين راضين عن شعورهم بانجاز أعمالهم وأهينتها. 
r-بالنسبة لمستوى الدعم والمساعدة من زملائك عندما نواجه مشكلة فى العمل، نجد أن

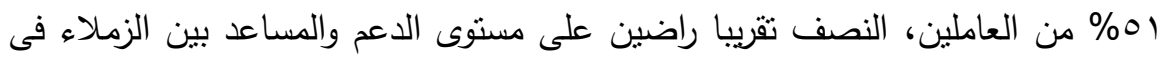

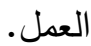

ع-بالنسبة لمستوى التقدير والمعاملة العادلة التى تحصل عليها من رئيسك المباشر ، نجد أن

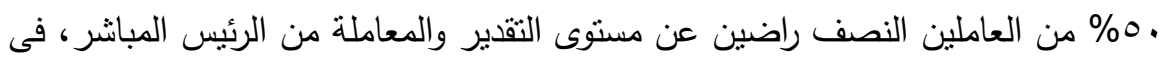
حين أن النصف الأخر غير راضى عن ذلك.

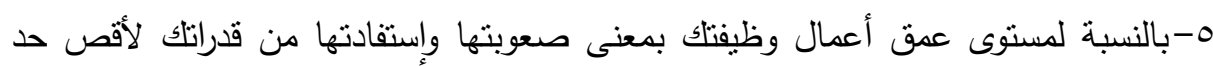
ممكن، نجد أن 9٪\% من العاملين النصف تقريبا يرون أن أعمالهم تسفاد من قدراتهم لأقص حد، أما النصف الأخر فيرى ان لديهم قدرات لا يستفاد منها العمل.

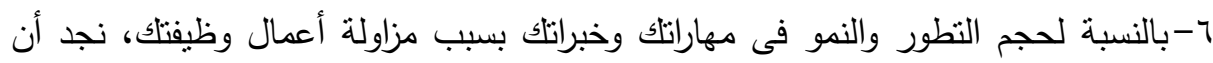

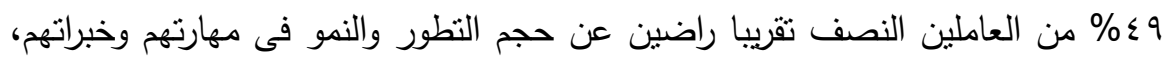
فى حين أن النصف الأخر غير راضى عن تطور ونمو مهارته وخبراته.

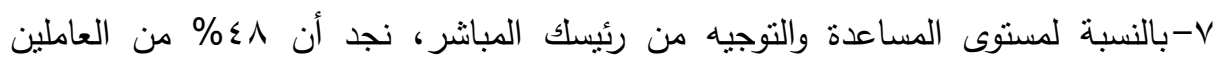

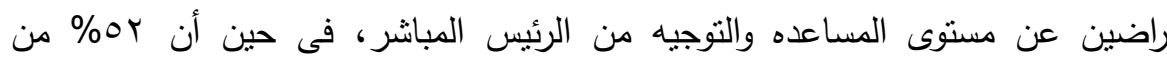

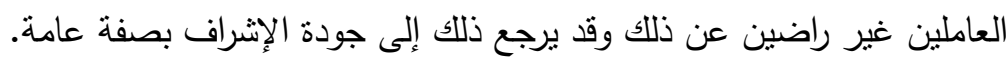

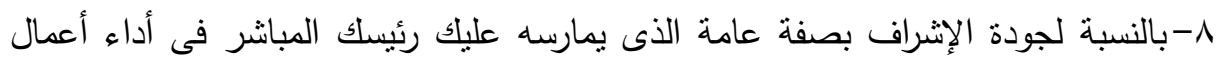

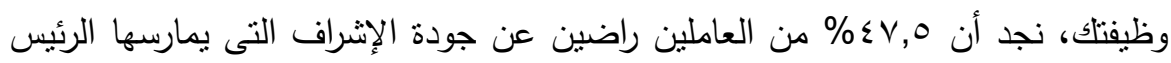

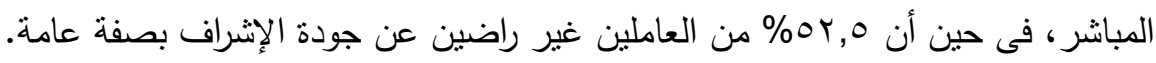

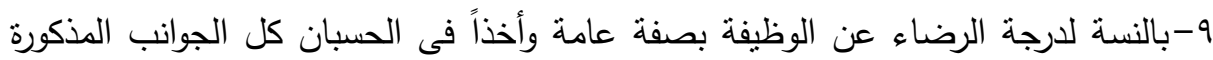

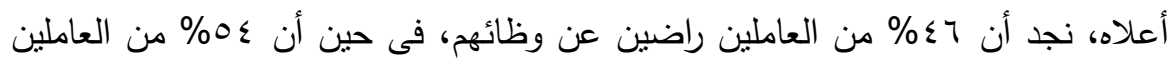
غير راضين عن وظائفهم وقد يرجع ذللك إلى جودة الإشراف والتوجية والمساعدة من

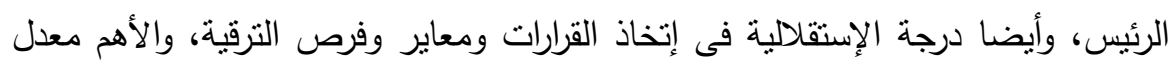
وعدالة العائد المادى من أجور وحوافز وومزايا إضافية. 
• 1-بالنسبة لارجة الإستقلالية التى تتمتع بها فى إتخاذ قرارات وظيفتاك وتصريف أمورها،

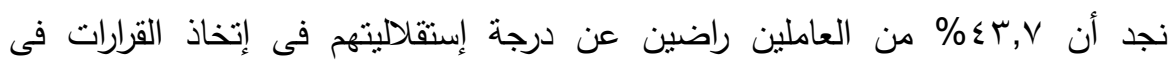

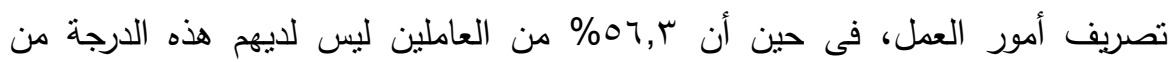
الاستقلالية .

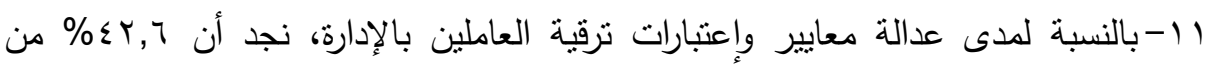

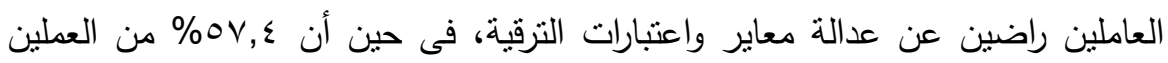

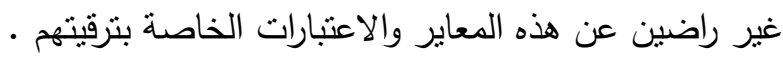

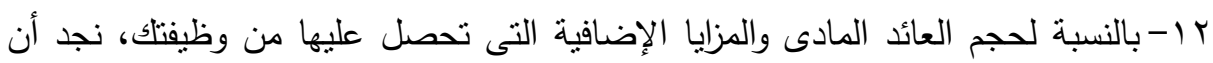

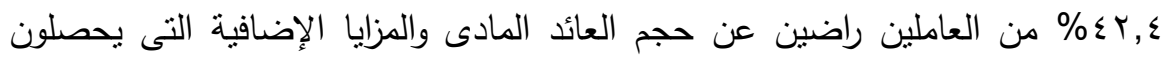

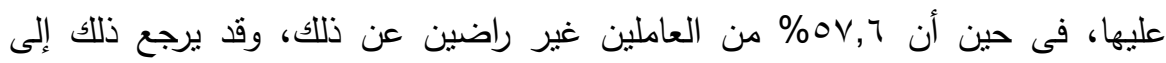

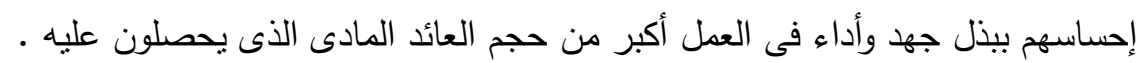

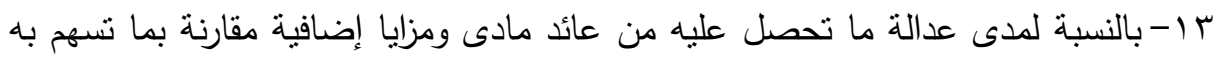

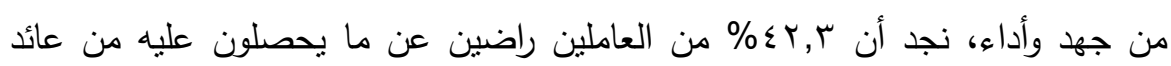

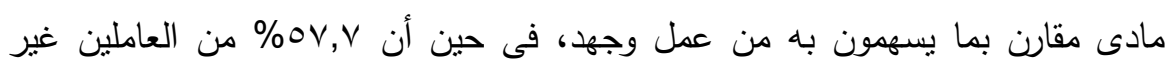

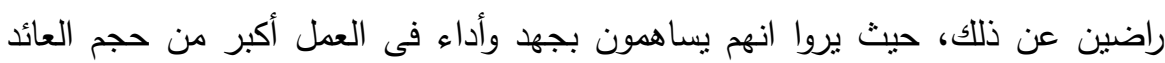
المادى الذى يحصلون عليه.

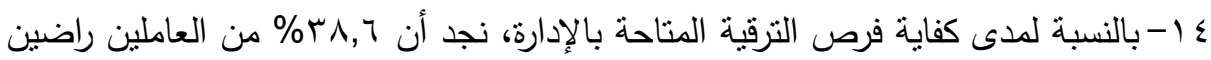

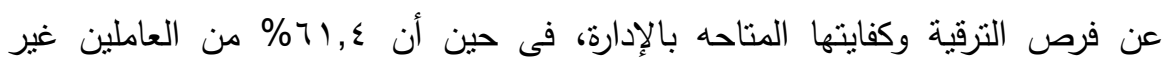
راضين عن فرص الترقية وكفايتها، وقد يرجع ذلك إلى أن عدد العاملين بالإدارة كبير مها يقلل فرص الترقية بالنسبة لهم . 
r- إختبار الفرض: الذى ينص على أنه " لا يوجد تأثير معنوي ذو دلالة إحصائية لاعادة

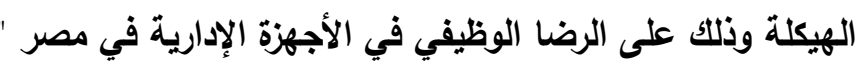

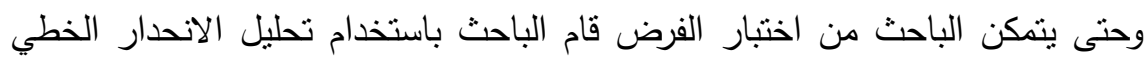

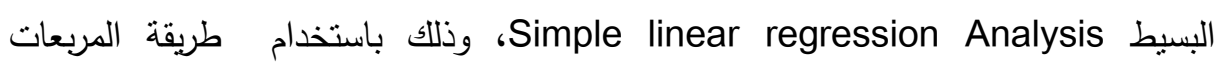
الصغرى Ordinary Least Squares (OLS)، بالإضافة لاختبارات معالم الانحدار

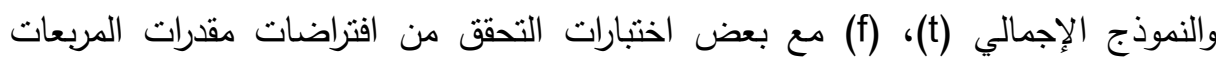
الصغرى وأسفرت نتائج التحليل الإحصائي للباحث في هذا الفرض على لإنى النتائج التالية: المتغير التابع: الرضا الوظيفي جدول رقم(؛): اختبار معاملات الانحدار ونتائج الارتباط للفرض الفرعي الثاني من الفرض لرض

\begin{tabular}{|c|c|c|c|c|c|c|}
\hline 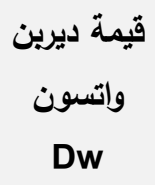 & معامل ارتباط & $\begin{array}{l}\text { القزار عذد } \\
\alpha=0.05\end{array}$ & مستوى الدلالة & قيمة t & معامل & المستقل \\
\hline $1, \wedge 9 \vee$ & • & معنوي & $\cdot, \cdot$ & 17,7 & $\cdot, 791$ & إعادة الهيكلة \\
\hline
\end{tabular}

جدول رقم(•): تحليل التباين ANOVA للفرض الفرعي الثاني من الفرض الرئيس الأول

\begin{tabular}{|c|c|c|c|c|c|c|}
\hline النسبة الغير & $\begin{array}{c}\text { معامل }{ }^{2} \text { التحديد } \\
\end{array}$ & $\begin{array}{l}\text { القرار عند } \\
\alpha=0.05\end{array}$ & مستوى الدلالة & قيمة F & الحرية & الاختلاف \\
\hline$\% \circ 0,7$ & $\% \varepsilon \varepsilon, \varepsilon$ & معنوي & $\cdot, \cdot$ & $r \wedge 1, r$ & $\begin{array}{c}1 \\
\text { ror }\end{array}$ & الانحدار \\
\hline
\end{tabular}

قيم جدولية مستخرجة من جداول ديربن وانسون DU =1.688 Du=1.701 DW من النتائج السابقة يتضح للباحث ما يلي:

أ- من جدول اختبار معاملات الانحدار ونتائج الارتباط:

1-كانت قيمة مستوى الدلالة الخاص باختبار اثز إعادة الهيكلةعلى الرضا الوظيفي اقل من قيمة مستوى المعنوية $\alpha$ = ○.,.•، وهذا يعنى وجود تأثير معنوي ذو دلالة إحصائية 
r-كانت إثنارة كل من معامل ارتباط بيرسون وكذلك معامل الانحدار الوارد إثنارة موجبة وهذا يعنى وجود علاقة طردية معنوية ذات دلالة إحصائية بين إعادة الهيكلة والرضا الوظيفي أو بعبارة أخرى كلما زادنإعادة الهيكلة أدى ذلك بدوره لزيادة الرضا الوظيفي في الأجهزة

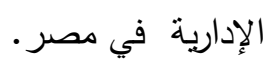

\section{بNOVA بن جدول تحليل التباين}

ا-كانت قيمة مستوب الدلالة لاختبار معنوية النموذج الإجمالي (F) اقل من قيمة مستوى الدلالة $\alpha=$ ه ., . ، وهذا يعنى إمكانية الاعتماد على النتائج المقدرة وكذلك إمكانية تعميم

$$
\text { نتائج العينة على مجتمع الدراسة. }
$$

r-كانت قيمة معامل التحديد

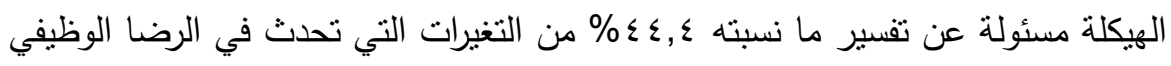

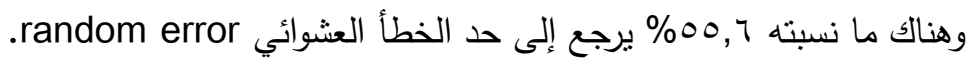

\section{ج- التحقق من افتراضات المربعات الصغرى :}

ا-لاختبار مشكلة الارتباط الذاتي بين بواقي الانحدار Auto correlation كانت قيمة إحصائية ديربن واتسون المحسوبة A9V = Dw, ا ، وبالنظر للقيم الجدولية يتضح للباحث أن القيمة المحسوبة تقع بين القيمتين الجدوليتين (Du, 4- Du)، وهذا يعنى عدم وجود تام لمشكلة الارتباط الذاتي.

مما سبق يمكن للباحث رفض الفرض العدمي وقبول الفرض في صورته البديلة التي

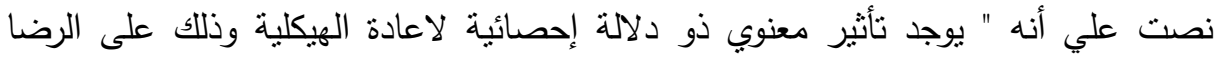
الوظيفي في الأجهزة الإدارية في مصر" بمعنى أن إعادة الهيكلة للعاملين ووضع كل عله عامل دله فى مكانه المناسب حسب قدراته ومهاراته، ومستوى تعليمه داخل الأجهزة الإدارية سوف يؤدى بدورة إلى الرضا عن العمل ورفع الروح المعنوية لهم مما يؤدى إلى الرضا الوظيفى •

$$
\text { المجلد الخامس والثلاثون الجزء الاول ديسمبر } 17 \text { ـr }
$$




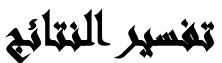

1-نصف العاملين تقريبا راضين عن مستوى التقدير والمعاملة العادلة التى يحصلون عليها من رئيسه المباشر، وأيضا مستوى عمق أعمال وظيفتهم، وحجم التطور والنمو فى لى

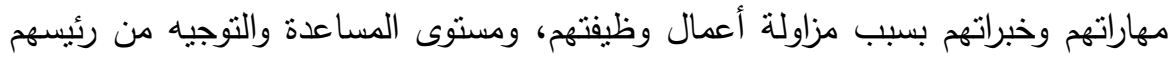

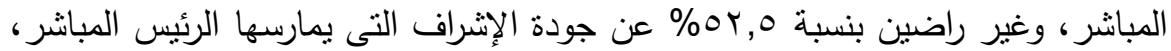

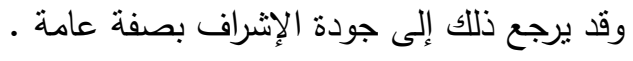

r-إن ؟0\% من العاملين غير راضين عن الوظيفة بصفة عامة، وأن r, ب0\% منهم ليس لديهم استقلالية فى إتخاذ القرارات فى تصريف أمور العمل، وقد يرجع ذلك إلى جودة الإشراف والتوجية والمساعدة من الرئيس، وأيضا درجة الإستقلالية فى إتخاذ القرارات ومعاير وفرص التزقية، والأهم معدل وعدالة العائد المادى من أجور وحوافز وومزايا

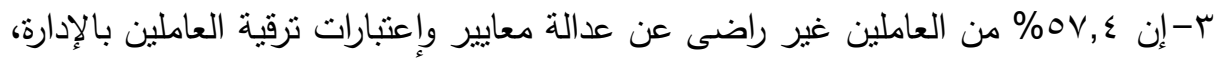

وقد يرجع هذا إلى أنهم من نفس الدرجات والهجموعات الوظيفية داخل الإدارة.

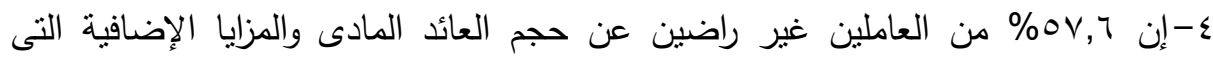

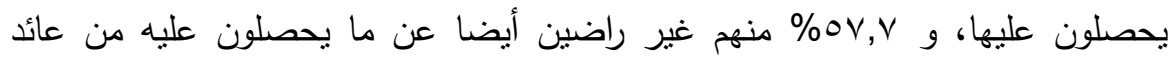

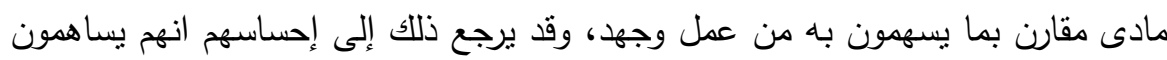

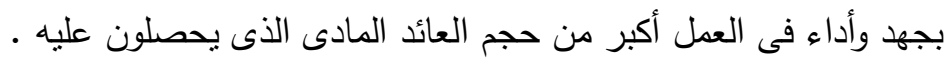

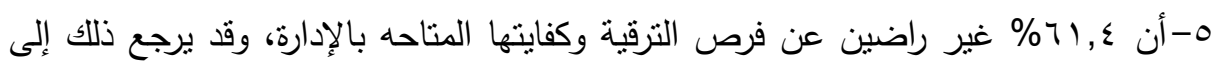

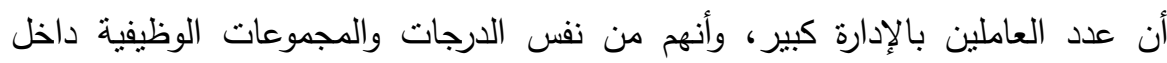

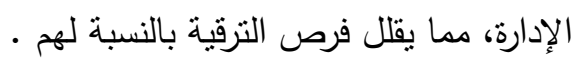
1-يوجد تأثير معنوي ذو دلالة إحصائية لاعادة الهيكلية وذللك على الرضا الوظيفي في بلهي

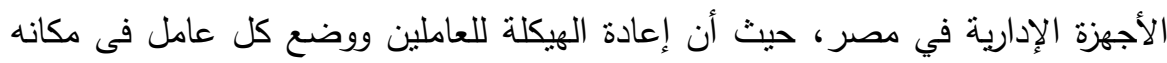
المناسب حسب قدراته ومهاراته، ومستوى تعليمه داخل الأجهزة الإدارية سوف يؤدى بدورة

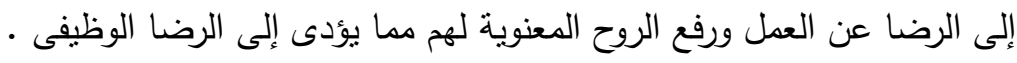




\section{الليوكيايت}

ا- أعطاء حرية لإدارة الموارد البشرية بين مختلف الإدارات لنقل الإفراد العاملين، وخصوصاً

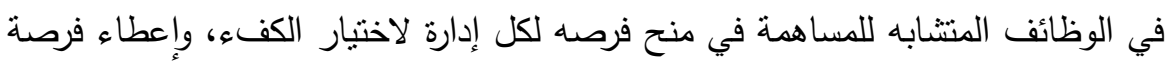

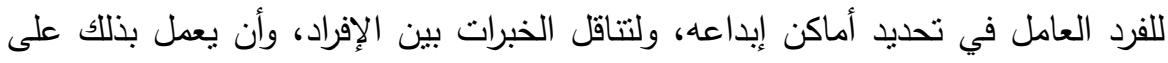

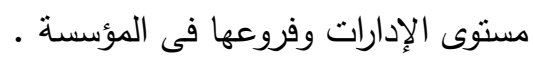

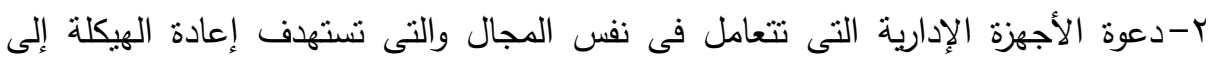

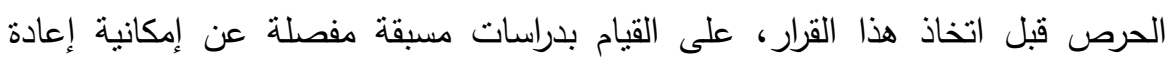

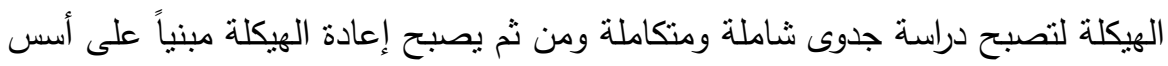

$$
\text { وضوابط موضوعية . }
$$

r-يتوجب على الإجهزة الإدارية بإعادة النظر في الرواتب والحوافز والمكافأت المادية للموظفين بحيث تكون أكثر ملائمة مع متطلبات الحياة المعيشية لهم، وذلك من شألأنه توليد

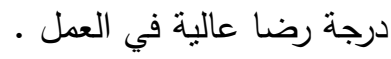

ع-يتوجب على المنظمة أن تضع نظم للحوافز سواء المادية أو المعنوية لحث الأفراد على دلى

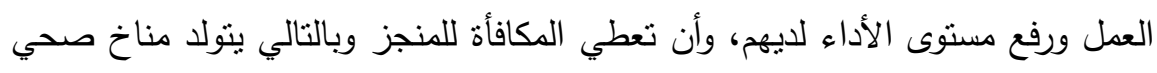
مما يحقق الرضا الوظيفي، وذلك من خلال البحث في دوافع الموظفين كي يقدم لهم التحفيز المقابل والمناسب مما يجعلهم يزيدون من محاولاتهم وجهودهم، وترشيح المتميزين

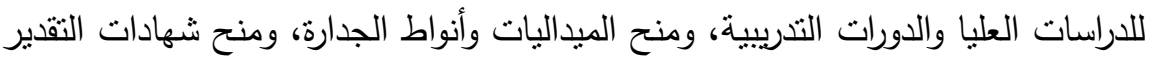
وخطابات الثكر ، ووضع الأوسمة بلوحات الثرف.

\section{zall}

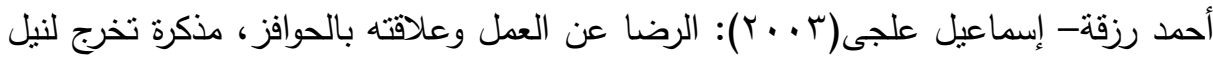

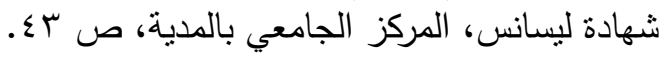

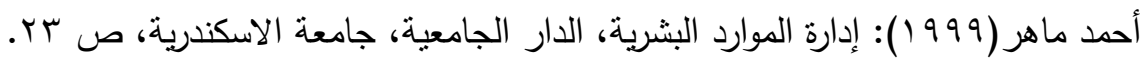

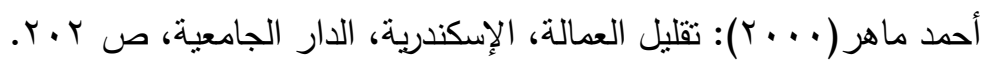

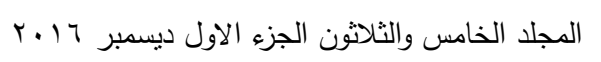




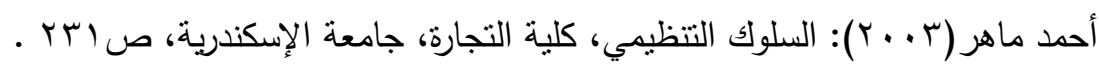

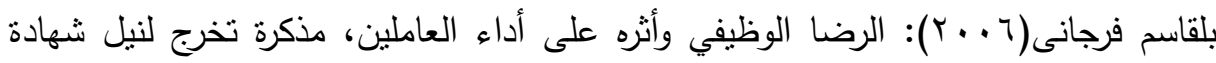

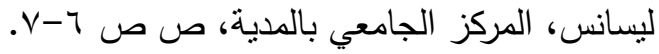

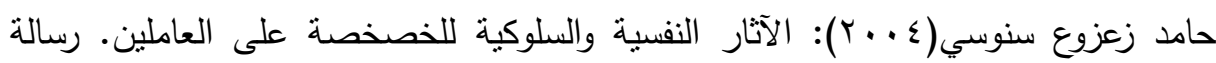

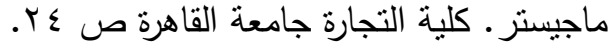

حسين حريم(997) (19): السلوك التظظيمي : سلوك الإقراد في المنظمات ، دار زهران للنشر

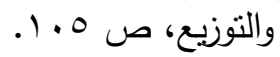

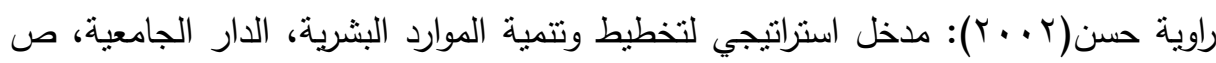
ص

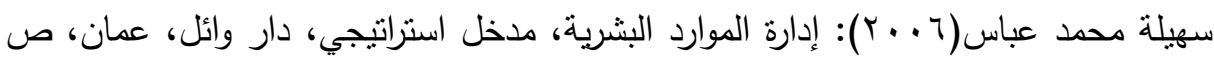
. IVV-IVT ص

صبرى أحمد شلبى(r(ب): رسالة ماجستير بعنوان " دور الحوكمة في الإصلاح الإداري

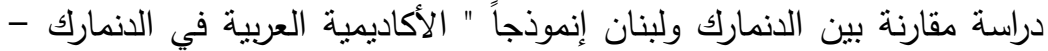
كلية القانون والسياسة - قسم القانون، ص صن 00.

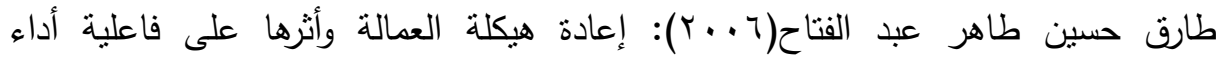

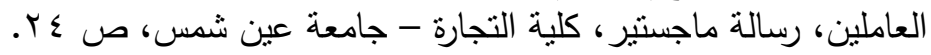

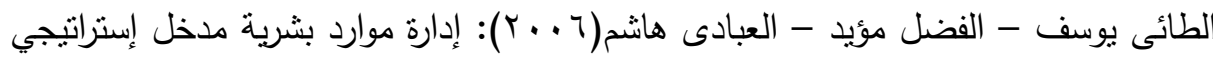

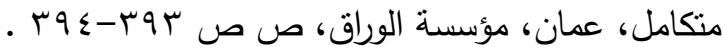

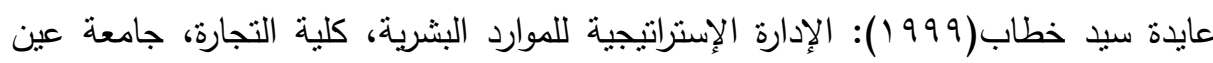

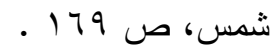

محمد سعيد سلطان(99V (19): السلوك التنظيمي، سلوك الأفراد في المنظمات، دار زهران

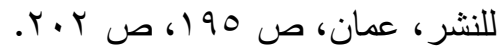

مصطفى عشوي(Y991): أسس علم النفس الصناعي، المؤسسة الوطنية للكتاب، الجزائر،

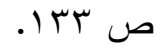

أحمد الكردي(· (•r): العوامل المؤثرة في الوضع التظيمي لأدارة الموارد البشرية http://kenanaonline.com 


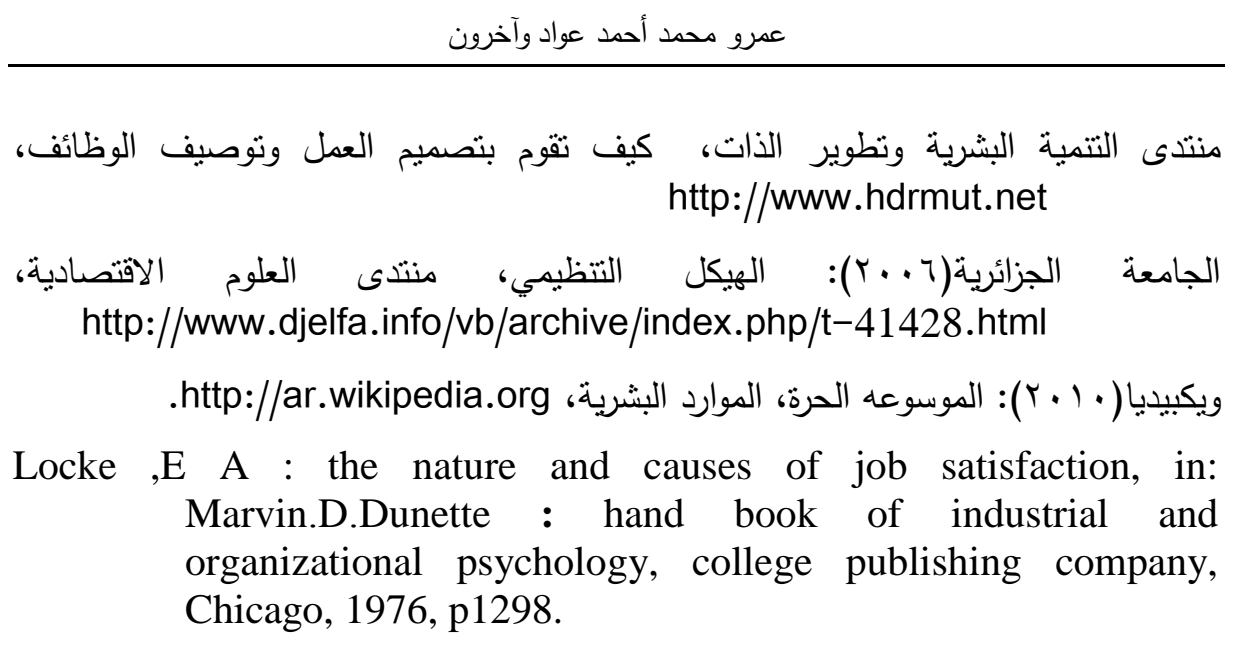

\title{
THE IMPACT OF RESTRUCTURING ON JOB SATISFACTION IN THE WORK ENVIRONMENT IN THE ADMINISTRATIVE ORGANS IN EGYPT
}

Awad, A, M. ${ }^{(1)}$; Al- Shahat, T. M. ${ }^{(1)}$ and Ahmed, A. M. A. R. ${ }^{(2)}$ 1) Faculty of Commerce, Ain Shams University. 2) Cairo University

\begin{abstract}
The research aimed to study the problem of the job satisfaction through the environment work in the administrative services and the impact of restructuring on it. There is undesirable situation in the public administrative organs in Egypt, reflecting a decrease in the quantitative and qualitative performance and decline the ability to export and the vulnerable to adapt to constant changes of the internal and external environments. This led us to the fundamental question which the impact of the restructuring on job satisfaction in the environment works of the administrative organs in Egypt.
\end{abstract}

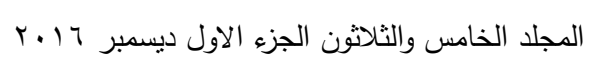




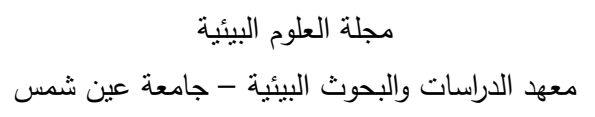

The researchers adopted on achieving the objectives of the study on the descriptive approach through the use of desktop scanning to take advantage of books and scientific journals in the construction of the theoretical framework through books and references Arab and foreign, Arab and foreign periodicals, research reports, and articles on the subject of the study، And analytical method of reconnaissance, which aimed to determine the problem of the study accurately study, so its personal interview to some administrative employment of workers at Cairo University Road, field use method in the collection of data by designing a questionnaire that was distributed to the study sample in subsequent stages of the study, was designed form manner, "Likert" on the five-scale trend, the use of multiple regression to determine the relationship between restructuring and job satisfaction analysis method, the study population consists of workers at Cairo University and the study sample was 377 Single of the various university administrative groups.

The concluded of the study that "there is a significant statistical effect of the restructuring on development of the human resources in the administrative organs in Egypt". That is meaning that the restructuring of the workers and the status of each worker in its appropriate place according to his capabilities, skills and his level of education within the administrative organs, according to his training, knowledge and organizational learning which will in turn lead to the development of human resources, Also, 54\% of workers are unhappy about the job in general, and that $56.3 \%$ of them do not have the independence in decision-making in the conduct of business matters, may be due to the quality of supervision, guidance and assistance from the main, and also the autonomy degree of decision-making and standards and promotion opportunities, and most importantly the rate and yield of the material justice wages and incentives and additional Omzaya. 